\title{
初中语文教学中的阅读与写作如何有机结合
}

吴小霞

甘肃省天水市秦安县刘坪中学

DOI:10.32629/jief.v2i9.1724

[摘 要] 初中语文在学生的初中学习阶段占据重要部分, 是提升学生语文素养的关键, 新形势下, 将初中语文阅读教学与写作教学进行结合 有利于提升学生的知识运用能力。本文阐述了在初中语文教学中将阅读与写作进行有机结合的重要意义, 并提出了一些优化阅读和写作结合 的措施。

[关键词] 初中语文; 阅读教学; 写作教学; 有机结合; 措施

中图分类号: G633.33 文献标识码: A

在新课程改革背景下, 以往的教育模式已经不能满足当前社会发展 的需求, 因此, 必须对学校教育进行改革。在初中语文阅读教学中, 学 生对文章进行品读和鉴赏, 通过阅读, 学生能够了解文章的大致内容以 及情感主线, 能够摘录其中较为优美的句子, 也能够掌握文章中应用了 哪些修辞手法以及使用这些修辞手法带来的效果, 对于提升学生的人文 素养具有很大的意义。学生如果能够将在阅读课中学到的知识灵活应用 到写作中, 对于创作的质量将会是一个很大的提升, 将两者进行有机结 合能够使学生的学习效果更佳。

1 在初中语文教学中将阅读与写作进行有机结合的重要意义

在初中阶段, 将阅读和写作进行有机结合具有十分重要的意义。第 一, 提升学生的注意力, 学生在进行文章阅读时会时刻思考能否将其中 比较优美的句子应用到自己的写作之中, 阅读注意力就会提高, 对于文 章中写的较好的句子或者写作手法就会主动摘抄下来, 并在自己的写作 中加以应用。第二, 使学生的学习兴致更高, 如果将阅读教学和写作教 学单独进行, 学生往往提不起学习的兴趣。而将阅读和写作结合起来进 行教学能够使教学模式更加多样化, 学生可以边阅读边进行创作, 在阅 读中进行创作, 在创作中应用阅读积累的素材及技巧, 另外, 将积累的 素材应用到创作中会使学生的写作质量明显提高, 学生会有成就感, 从 而提升语文学习的兴趣。

\section{2 初中语文教学中阅读与写作有机结合的措施}

2.1 利用阅读活动积累写作素材

初中语文阅读教学和写作教学是一个积累的过程, 不能一䟽而就。 所以, 初中语文教师要积极利用阅读教学, 教授学生如何正确进行阅读, 使学生在阅读过程中能够形成一个良好的习惯, 及时对阅读内容中的句 子进行摘录, 使学生在阅读过程中为写作练习积累大量的写作素材。例 如, 在学习《春》时, 这篇文章使用了大量的比喻和拟人的修辞手法, 赋予了春天别样的生机, 使春变得生机盘然, 表现了春天的鲜艳、美丽 和具有强大生命力的特点。教师可以要求学生对文章的句子进行记录摘 抄, 使学生在写作练习中遇到景物描写和季节描写的题目时, 能够学习 朱自清《春》中的描写方式, 使学生的写作作品变得丰富多彩, 更具层 次感。

\section{2 利用写作任务提高学生的阅读兴趣}

在写作教学中, 语文教师可以把写作任务与阅读任务联系起来, 在 写作作业中融入阅读任务提高学生对语文阅读的兴趣。教师可以要求学 生自己选择课外读物, 根据自己的观点对课外读物进行解读, 同时根据 自己阅读的感受完成写作任务。例如, 教师可以要求学生阅读《活着》 这一小说, 并针对其中发生的故事情节以及阅读感受、作者情感等完成 读后感写作任务。在这一任务中, 能够引导学生对小说内容进行深思, 使学生体会到小说作者的情感, 了解当时社会的基本情况。此外, 教师 还可以要求学生对自己选择的课外读物进行评价或赏析, 与学生一起研 究阅读内容的写作思路和写作手法, 帮助学生掌握文章结构和写作方式, 使学生体会到阅读和写作过程的轻松愉悦。

2.3 利用趣味阅读提高学生的写作兴趣
兴趣对于初中语文教学中阅读和写作的有机结合至关重要, 浓烈的 兴趣能够激发学生的求知欲和探究能力。所以, 初中语文教师要巧妙利 用阅读教学, 提高学生对于写作教学的兴趣, 使学生积极学习写作知识 和写作技巧。教师可以在阅读教学活动中利用趣味阅读, 结合学生的兴 趣布置阅读任务, 让学生在趣味阅读中感受作者的写作手法和语言的运 用, 培养学生主动运用阅读中的写作方式进行写作练习的意识, 使学生 体会到写作的乐趣。例如, 小明同学喜欢飞机模式, 教师根据小明的喜 好可以为他推荐与飞行、航空、航天等有关的书籍、期刊, 使小明更加 深入的了解相关的知识。并让小明将书籍中描写飞行、航空等知识的语 句进行摘抄, 根据摘抄的语句和自己的感受进行写作练习, 题目自拟。 将学生的兴趣与教学活动相结合能够激发学生求知欲, 使学生积极自主 的投入到学习中, 寓教于乐。

2.4 结合生活素材进行阅读写作练习

初中语文教学的生活化能够增加教学课堂的趣味性, 也能够给学生 提供更多的阅读素材, 对于学生在写作过程中情感的表达具有一定的帮 助, 因此, 初中语文教师在进行阅读写作的教学时应当充分利用生活实 例。例如, 在学习《回忆我的母亲》的时候, 教师可以要求学生回忆自 己的母亲, 想一想自己和母亲之间发生了哪些事情, 自己对哪些事情的 印象比较深刻, 然后要求学生写一篇关于母亲的文章。在这个过程中, 学生能够逐渐感受到文章中作者的真实感受, 从字里行间感受到母亲对 孩子的爱, 以及作者对于母亲的感恩, 在写作过程中学生也会联想自己 的母亲对自己的关爱, 在将与母亲之间发生的事情描写出来时感情会更 加真挚。是学生讲自己的真情实感融入到文章中, 进而提升作品档次。

\section{3 结束语}

总而言之, 将初中语文阅读与写作相结合进行教学符合当前教育教 学的理念, 对于初中生语文素质的提高具有很大的帮助。利用学生的兴 趣提高学生对阅读教学和写作教学的积极性, 学生会提高自主学习兴趣, 利用课外阅读活动能够扩展学生的阅读面, 使学生积累更多的写作素材。 同时还要结合生活素材对学生的阅读和写作能力进行训练, 使学生能够 亲身感受到大自然的魅力, 更好地体会文章作者的情感, 学习作者的写 作方式，将自己的情感赋予到创作的文章中。

[参考文献]

[1]白素华.初中语文阅读与写作有机结合的教学思考——以读悟写 [J].基础教育论坛,2020(01):16-17.

[2]谢丽丹.试论在初中语文写作教学中运用情景教学法[J].名师在 线,2019(18):66-67.

[3] 励德明. 初中语文读写结合教学策略 [J]. 文化创新比较研 究,2017,1(35):48+50.

[4]龙卫海. 初中语文课内外阅读教学和写作教学结合技巧探索 [J]. 中国校外教育,2017(21):1-2+8.

[5]曾敏. 探讨初中语文阅读与写作教学的有机结合 [J]. 亚太教 育,2016(16):45. 